\title{
Correction to: Challenges and Opportunities in the Selective Laser Melting of Biodegradable Metals for Load-Bearing Bone Scaffold Applications
}

D. CARLUCCIO, A.G. DEMIR, M.J. BERMINGHAM, and M.S. DARGUSCH

https://doi.org/10.1007/s11661-020-05829-7

(C) The Minerals, Metals \& Materials Society and ASM International 2020

\section{Correction to: \\ Metallurgical and Materials Transactions A \\ https://doi.org/10.1007/s11661-020-05796-z}

IN the original article, Figures 1 and 2 are incorrect.

Following are the correct figures.

D. CARLUCCIO, M.J. BERMINGHAM, and M.S. DARGUSCH are with the School of Mechanical and Mining Engineering and Queensland Centre for Advanced Materials Processing and Manufacturing (AMPAM), The University of Queensland, St Lucia, QLD 4072, and also with the Australian Research Council Research Hub for Advanced Manufacturing of Medical Devices, St Lucia 4072, Australia. A.G. DEMIR is with the Department of Mechanical Engineering, Politecnico di Milano, Via La Masa 1, 20156 Milan, Italy. Contact e-mail: aligokhan.demir@polimi.it

The original article can be found online at https://doi.org/10.1007/ s11661-020-05796-z.

Article published online May 27, 2020 

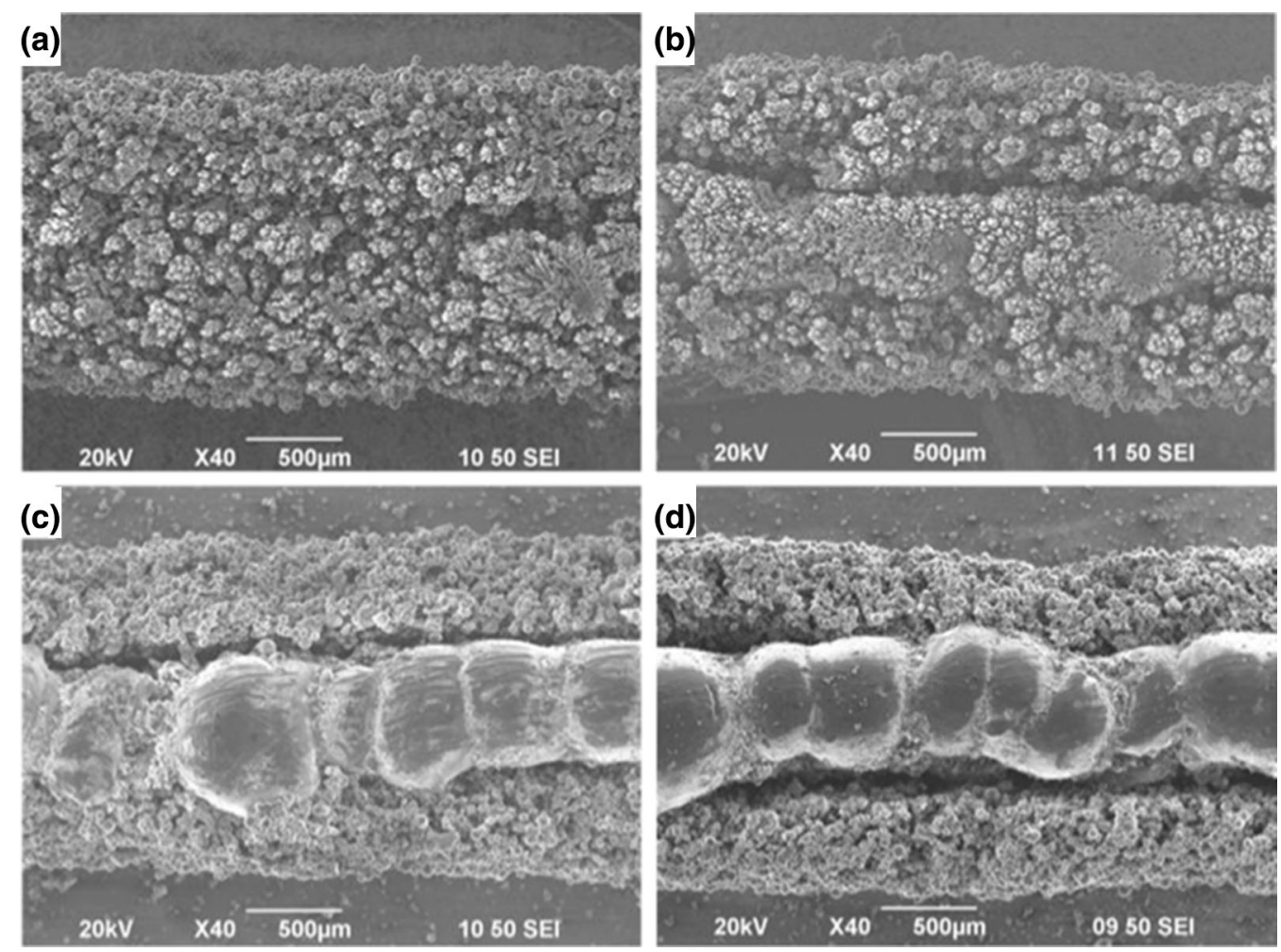

Fig. 1-SEM images of surface morphology of pure Mg processed with a linear energy density of $(a) 0.33 \mathrm{~J} / \mathrm{mm}^{2},(b) 0.66 \mathrm{~J} / \mathrm{mm}^{2},(c) 0.99$ $\mathrm{J} / \mathrm{mm}^{2}$, and $(d) 1.33 \mathrm{~J} / \mathrm{mm}^{2}$. Reproduced with permission from Ref. [257].
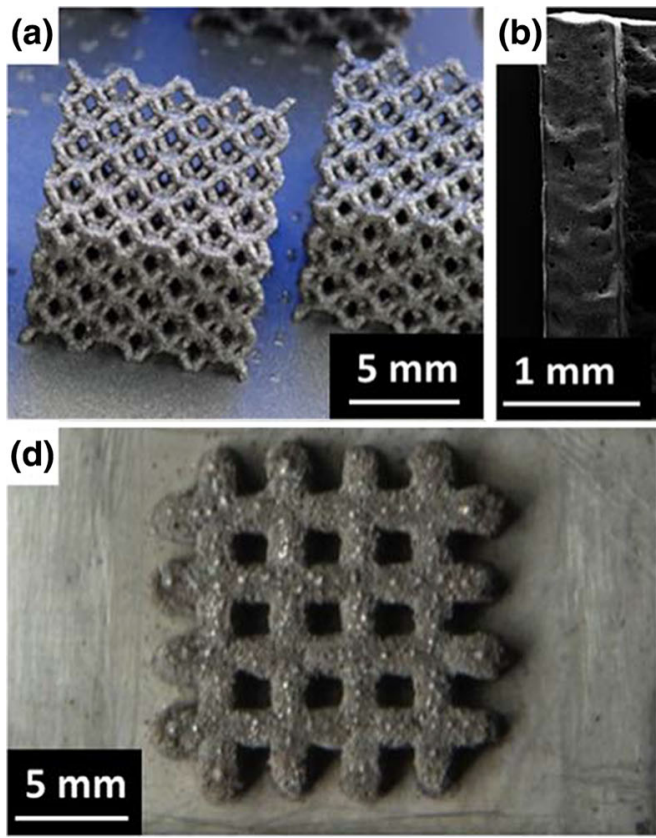

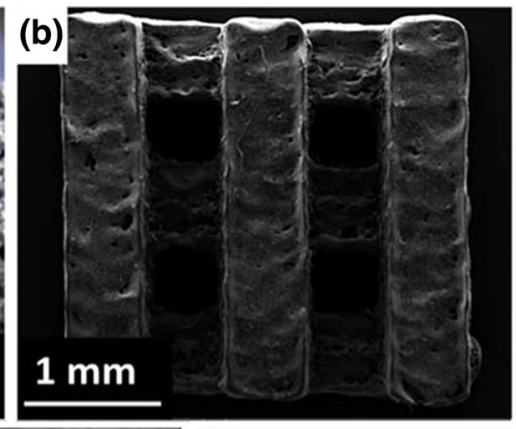

(e)

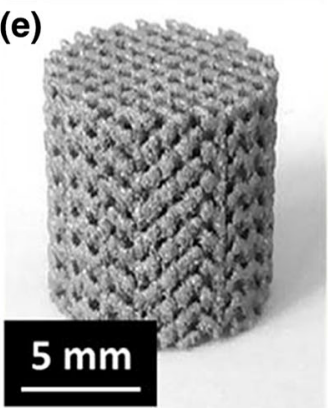

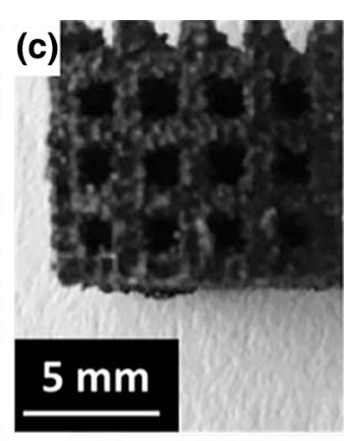

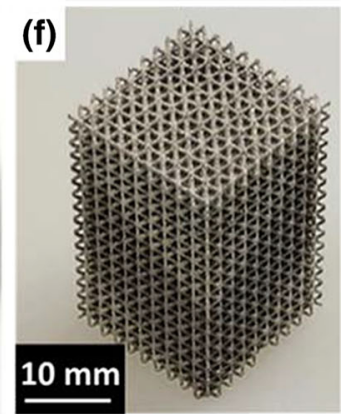

Fig. 2-Magnesium-based selective laser-melted scaffolds. Reproduced with permission from (a) Ref. [282]. (b) Reprinted from Ref. [281], under the terms of the Creative Commons CC BY license, (c) Ref. [283], (d) Ref. [270], (e) Ref. [284], and (f) Ref. [285]. 